\title{
Domestic Injuries and Physical Agents: A Disregarded Health Issue among Housewives in Raipur, India
}

\author{
Mondal $\mathrm{J}^{1}$, Bhattacharjee $\mathrm{T}^{2}$ \\ ${ }^{1}$ Research Scholar, ${ }^{2}$ Professor, Department of Nursing, NIMS University Rajasthan, Jaipur, India.
}

\section{ABSTRACT}

Introduction: Housewives perform various household works both inside and outside the home, which may cause domestic injuries and ill health. Domestic injuries are usually sustained due to exposure to various physical agents. The objectives of the current study were to find out the various physical agents, the prevalence of various types of domestic injuries \& to find out the association between domestic injuries and selected physical agents.

Methods: In this study 500 housewives aged more than 18 years from villages of Raipur, Chhattisgarh were selected by multistage stratified random sampling. Demographic information, the occurrence of domestic injuries, and the factors associated with injuries were collected by questionnaires, interviews, and observation technique. Collected data were analyzed by using SPSS 16 statistical package.

Results: Results showed that the mean age of housewives was $39.27( \pm 12.07)$ years and the majority of them were between 22-35 years of age group. Data revealed that $59 \%$ of housewives had suffered from domestic injuries. Out of them, the majority were suffering from vision problems (45.1\%) and headache (36\%), $21 \%$ suffered from heat, $15 \%$ got cut and $14.8 \%$ had fire burn from home environment. Around $14 \%$ got eye irritation and $12.8 \%$ of housewives had experienced falls on the floor. A significant association was found between injuries and physical agents.

Conclusion: The study concluded that housewives are exposed to various physical agents in their own homes, which contributes to the prevalence of various types of domestic injuries among them. Housewives themselves and family members have to be aware of those physical agents present in their home which silently affecting their health.

Key words: Domestic Injuries, Housewives, Physical agents, Relative humidity, Vision problem

\section{Introduction}

$\mathrm{H}$ ousewives are involved in various domestic chores in their daily life. Their general routine and lifestyle

DOI: https://doi.org/10.3126/ijosh.v11i2.34160

Conflicts of interest: None

Supporting agencies: None

Date of submission: 08.01.2021

Date of acceptance: 20.04 .2021

Date of publication: 30.04.2021

\section{Corresponding Author}

Jaita Mondal

Research Scholar,

NIMS College of Nursing,

NIMS University Rajasthan; Jaipur; India.

E-mail ID: jaidolsmon@gmail.com

Mob. No.- +916394523995

ORCID ID: https://orcid.org/0000-0003-2999-6983 pose several threats and leads to domestic injuries. Generally, women's works at home are numerous but not recognized. They are usually involved in various household work both inside and outside the home, which causes accidents and ill health. Apart from their strenuous domestic chores, rural Indian women are engaged in different agricultural works too.

While working at home, three types of interaction occur between housewives and the environment. These are physical agents, chemical agents, and mechanical agents. Few examples of physical agents are heat, cold, humidity, noise, light, vibrations, etc.; chemical agents are like cleaning solutions, acids to clean

\section{(c) (7) \&}

This journal is licensed under a Creative Commons AttributionNon Commercial 4.0 International License. 
floor or toilet; mechanical agents are those machines housewives use frequently at home as mixer grinder, knives, or other sharp instruments, rice cookers, toasters, etc. ${ }^{1}$

The house is principally seen as a zone of solace from the rest of the world which is also accepted to be the place for accidents. A household accident may occur inside the house, as well as in the surroundings which is one of the four significant reasons for death on the planet. Domestic accidents are probably going to happen because of steady activities in homes and their environs at which different home appliances are constantly used. Accidents at home never ought to occur, they are constantly brought about by preventable mistakes. ${ }^{2}$

In some European nations, accidents at home exterminate a greater number of individuals than on street. The Large Analysis and Review of European lodging and wellbeing Status study of the WHO Regional Office for Europe detailed cuts as the most common accident followed by falls and burns. ${ }^{3}$

The important reasons for significant domestic accidents are:

- Individuals' cognitive failure or un-mindfulness at Kitchen, most particularly working at gas.

- Uncovered and unattended Electrical Connections, Electrical associations could likewise be hazardous and have a lethal endpoint.

- Poor Sanitary Maintenance as wet floors, litter around the house can cause hazards as an individual could slip and fall hitting on a hard edge. ${ }^{4}$

A previous investigation had discovered a casualty pace of $31.58 \%$ among females at household work. ${ }^{4}$ Another report on the domestic accident at Imphal, India recorded 287 domestic accidents with a $68.3 \%$ annual incidence rate. Cuts and lacerations (57.1\%) were the most well-known hazards experienced followed by falls (18.5\%), burn, and scald (13.6\%). The investigation detailed no disability and mortality coming out from these domestic accidents. ${ }^{5}$

In a developing nation like India information about the domestic injury is poor. Domestic injuries are a significant general health problem and the issue is graver in rural India. Domestic injuries are one of the five driving reasons for death in industrialized and developing countries. ${ }^{6}$ This current investigation was led to discover the various physical agents, the prevalence of various types of domestic injuries \& also to find out the association between domestic injuries and selected physical agents among the Indian Rural Housewives.

\section{Methods}

An exploratory and descriptive cross-sectional study with a quantitative approach was performed among 500 housewives aged more than 18 years from villages of Raipur, Chhattisgarh, India.

In the present study, the probability sampling (multistage stratified random sampling) technique was used to select the areas of Raipur. Every second house was chosen for data collection. If no housewife was found in that house, then the next house was selected. Inclusion criteria for this study were i) women who were housewives, ii) housewives who gave written consent to participate in the study, and iii) housewives who could understand Hindi, and the exclusion criteria were; housewives who came from another district rather than Raipur.

Data on demographic information, the occurrence of domestic injuries, and factors associated with injuries were collected by questionnaires, interviews, and observation techniques.

Physical parameters were measured by the instruments like measuring tape, weighing machine.

Factors causing domestic injury were measured by the mentioned instruments, i) Lux meter was used to measure illumination, ii) noise level was measured by the sound level meter, and iii) relative humidity and the room temperature was measured with an anemometer.

The content validity of the tools was ensured by giving them to seven experts $(C V I \geq 0.7)$. The reliability of the instruments was checked by administering to 20 samples $(r \geq 0.8)$.

Data were analyzed based on the study objectives using descriptive and inferential statistics (SPSS 16).

\section{Results}

Results showed that the mean age of housewives was $39.27( \pm 12.07)$ years and a majority of them were between 22-35 years of age group. Maximum women were with a mean weight and height of $47.88( \pm 6.23)$ $\mathrm{Kg}$ and $152( \pm 5.54) \mathrm{cm}$ respectively with a mean BMI of $20.71( \pm 3.2)$. BMI denotes that the majority $(60.6 \%)$ had normal weight. Only $7 \%$ fall under pre obesity and $32.4 \%$ were underweight. 
This current study found that the mean illumination of the living room was 46.3 LUX $( \pm 38.29)$ (range $10-188$ LUX) and 63.69 LUX ( \pm 79.38$)$ (range $10-487$ LUX) at the kitchen. Fig. 1 denotes that $93.6 \%$ of the living room as well $98.4 \%$ of the kitchen of this community had low illumination. ${ }^{7}$

Table 1 shows that the mean noise level was 56.89 $( \pm 8.5) \mathrm{dBA}$ in the bedroom, $64.24( \pm 11.51) \mathrm{dBA}$ in the living room, and $55.54( \pm 7.8) \mathrm{dBA}$ in the kitchen. It was also found that high sound level $(100 \%)$ in the bedroom (>25dBA) and living room (>40 dBA) whereas at kitchen sound level was normal $(100 \%)$ i.e., within 40-90 dBA as per the standards. ${ }^{8}$

Table 2 and Figure 2 shows that mean relative humidity was $36.81( \pm 8.366) \%$ at a mean temperature of $41.3^{\circ} \mathrm{C}$ $( \pm 3.349)$ which refers to hot $(100 \%)$ and dry $(64.6 \%)$ kitchen environment.

Table 3 denotes that around $50 \%$ (45.2\%) house was not as per standards ${ }^{7}$ i.e.; no. of rooms was not adequate as per the no. of members residing at that house. In $63.4 \%$ of the house, there was no adequate natural light even artificial light was also not sufficient (54.8\%). In $86.4 \%$ of houses, there was no cross ventilation, even there was no window in the bedroom.

Fig. 3 and Fig. 4 show that $59 \%$ of housewives had suffered from domestic injury. Majority of them was suffering from vision problem $(45.1 \%), 36 \%$ had a headache, $21 \%$ suffered from heat, $15 \%$ got cut and $14.8 \%$ had fire burn from home environment. $13.8 \%$ also got eye irritation and $12.8 \%$ of housewives had experienced falls on the floor.

An Independent t-test was done to find out the association of various domestic injuries with selected physical agents at the level of 0.05 level of significance. Significant associations of cut, laceration, vision problem, hearing problem, headache, eye irritation with selected physical agents have been displayed in table 4.

Table 1: Average Noise Level of the existing rooms $(n=500)$

\begin{tabular}{ccccc}
\hline Variables & Minimum & Maximum & Range & Mean (SD) \\
\hline Bed Room & 34 & 89 & 55 & $56.89( \pm 8.5)$ \\
Living Room & 45 & 97 & 52 & $64.24( \pm 11.51)$ \\
Kitchen & 40 & 77 & 37 & $55.54( \pm 7.8)$ \\
\hline
\end{tabular}

Table 2: Description of Relative Humidity \& Temperature at Kitchen $(n=500)$

\begin{tabular}{ccccc}
\hline Variables & Minimum & Maximum & Range & Mean (SD) \\
\hline Relative Humidity $(\%)$ & 23.00 & 56.00 & 33.00 & $36.8( \pm 8.366)$ \\
Temperature $\left({ }^{\circ} \mathrm{C}\right)$ & 35.5 & 62.4 & 26.90 & $41.3( \pm 3.349)$ \\
\hline
\end{tabular}

Table 3: Description of other physical agents $(n=500)$

\begin{tabular}{lcccc}
\hline \multirow{2}{*}{ Variables } & \multicolumn{2}{c}{ Yes } & \multicolumn{2}{c}{ No } \\
\cline { 2 - 5 } & $\mathbf{f}$ & \% & 226 & f \\
\hline No. of rooms as per standards & 274 & 54.8 & 317 & 45.2 \\
Presence of adequate natural light & 183 & 36.6 & 274 & 63.4 \\
Presence of adequate artificial light & 226 & 45.2 & 432 & 54.8 \\
Windows situated as cross ventilated & 68 & 13.6 & 86.4 \\
\hline
\end{tabular}

Table 4: Association between various domestic injuries with selected physical agents $n=500$

\begin{tabular}{|c|c|c|c|c|c|c|c|}
\hline S.N. & Physical agents & Domestic Injuries & Mean & SD & df & t- value & $p$-value \\
\hline & & Cut & & & & & \\
\hline \multirow{2}{*}{1} & \multirow{2}{*}{ Illumination at living room } & Yes & 29.5 & 31.02 & \multirow{2}{*}{498} & \multirow{2}{*}{-3.15} & \multirow{2}{*}{$0.002^{*}$} \\
\hline & & No & 48.0 & 38.57 & & & \\
\hline \multirow{2}{*}{2} & \multirow{2}{*}{ Noise level at living room } & Yes & 58.94 & 11.75 & \multirow{2}{*}{498} & \multirow{2}{*}{-3.312} & \multirow{2}{*}{$0.001^{*}$} \\
\hline & & No & 64.78 & 11.37 & & & \\
\hline \multirow{2}{*}{3} & \multirow{2}{*}{ Noise level at Kitchen } & Yes & 58.58 & 9.43 & \multirow{2}{*}{498} & \multirow{2}{*}{2.778} & \multirow{2}{*}{$0.006^{*}$} \\
\hline & & No & 55.24 & 7.58 & & & \\
\hline
\end{tabular}




\begin{tabular}{|c|c|c|c|c|c|c|c|}
\hline S.N. & Physical agents & Domestic Injuries & Mean & SD & df & t- value & $p$-value \\
\hline \multirow{2}{*}{4} & \multirow{2}{*}{$\begin{array}{l}\text { Relative Humidity at } \\
\text { Kitchen }\end{array}$} & Yes & 34.21 & 7.85 & \multirow{2}{*}{498} & \multirow{2}{*}{-2.22} & \multirow{2}{*}{$0.027^{*}$} \\
\hline & & No & 37.07 & 8.37 & & & \\
\hline \multirow{2}{*}{5} & \multirow{2}{*}{ Temperature at Kitchen } & Yes & 42.29 & 3.26 & \multirow{2}{*}{498} & \multirow{2}{*}{2.123} & \multirow{2}{*}{$0.029^{*}$} \\
\hline & & No & 41.16 & 3.34 & & & \\
\hline \multicolumn{8}{|c|}{ Laceration } \\
\hline \multirow{2}{*}{6} & \multirow{2}{*}{ Noise level at living room } & Yes & 70.83 & 13.84 & \multirow{2}{*}{498} & \multirow{2}{*}{2.098} & \multirow{2}{*}{$0.036^{*}$} \\
\hline & & No & 64.07 & 11.41 & & & \\
\hline & & Fall & & & & & \\
\hline \multirow{2}{*}{7} & \multirow{2}{*}{ Noise level at Bed Room } & Yes & 51.97 & 6.99 & \multirow{2}{*}{498} & \multirow{2}{*}{-3.812} & \multirow{2}{*}{$0.0001^{*}$} \\
\hline & & No & 57.31 & 8.50 & & & \\
\hline 8 & Noico lovel ot L iving Ronm & Yes & 59.23 & 9.24 & 108 & 2851 & $\cap \cap \cap 5 *$ \\
\hline 0 & INUISe ievel da Living noum & No & 64.67 & 11.60 & 490 & -2.001 & 0.000 \\
\hline$a$ & Noico lovel at Kitchon & Yes & 61.35 & 2.99 & 108 & 1036 & $\cap \cap \cap \cap 1$ * \\
\hline y & 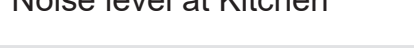 & No & 55.05 & 7.91 & 490 & 4.900 & 0.0001 \\
\hline & & Vision Problem & & & & & \\
\hline 10 & llumingtion at living ronm & Yes & 35.87 & 12.04 & 108 & 370 & ค คคค1* * \\
\hline 10 & 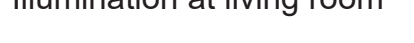 & No & 50.24 & 16.05 & 450 & -0.10 & 0.0001 \\
\hline 11 & llumination at Kitchen & Yes & 32.66 & 11.64 & 498 & -55 & $\cap \cap \cap \cap 1$ * \\
\hline 11 & IIU⿴囗十ा & No & 75.42 & 7.22 & 450 & -0.0 & 0.0001 \\
\hline & & Hearing Problem & & & & & \\
\hline 12 & Noise I evel at Kitchen & Yes & 48.9 & 10.43 & 498 & -3.376 & $\cap \cap \cap 1^{*}$ \\
\hline 12 & 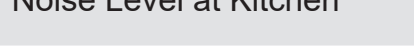 & No & 55.72 & 7.67 & 450 & & 0.001 \\
\hline 13 & Relative Humidity at & Yes & 42.38 & 6.74 & 100 & 2212 & 000 \\
\hline & Kitchen & No & 36.67 & 8.36 & 498 & 2.342 & $0.02^{n}$ \\
\hline 14 & Temnerature at Kitchen & Yes & 38.9 & 1.56 & 198 & & $\cap 012 *$ \\
\hline 14 & Iemperature at Kitchen & No & 41.32 & 3.36 & 498 & -2.489 & $0.013^{n}$ \\
\hline & & Headache & & & & & \\
\hline & Ulumination at living $\mathrm{romm}$ & Yes & 53.17 & 37.48 & 198 & 2130 & $0033 *$ \\
\hline 15 & Illumınatıon at IIving room & No & 44.36 & 38.33 & 498 & 2.139 & $0.033^{n}$ \\
\hline 16 & Humingtion ot Kitchen & Yes & 79.54 & 68.9 & 108 & 238 & $0 \Omega 10^{*}$ \\
\hline 10 & mumination at kitcnen & No & 59.24 & 81.62 & 498 & 2.38 & 0.018 \\
\hline 17 & Noico loyel ot living ronm & Yes & 58.78 & 9.69 & 108 & 5817 & ค คคค1 * \\
\hline 17 & Novise ievel da ining $100 \mathrm{~m}$ & No & 65.78 & 11.53 & 490 & -0.011 & 0.0001 \\
\hline 18 & Noise level at Kitchen & Yes & 57.0 & 10.01 & 498 & 2224 & $0027 *$ \\
\hline & Nolse revel al himchent & No & 55.13 & 7.04 & & & \\
\hline 19 & Relative Humidity at & Yes & 39.2 & 8.66 & 00 & 125 & $0 \cap 1$ * \\
\hline 19 & Kitchen & No & 36.14 & 8.17 & 498 & 3.425 & $0.001 n$ \\
\hline & & Eye Irritation & & & & & \\
\hline 20 & llumingtion ot living $\mathrm{ronm}$ & Yes & 31.86 & 19.74 & 100 & 2550 & $00110 *$ \\
\hline$\angle U$ & 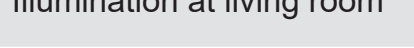 & No & 47.58 & 39.34 & 490 & -2.059 & 0.0110 \\
\hline 21 & Huminotion ot Kitchen & Yes & 43.67 & 76.12 & م0 & 2001 & * \\
\hline 21 & Illumınatıon at Kıtchen & No & 60.26 & 78.9 & 498 & 3.281 & $0.001^{\wedge}$ \\
\hline 22 & Noico lovel ot living ronm & Yes & 59.64 & 8.44 & 108 & 2751 & $\cap \cap \cap 6$ * \\
\hline 22 & INolse level at IIVIng room & No & 64.70 & 11.65 & 498 & -2.151 & 0.006 \\
\hline $22+2>>>2>3$ & Noico lovel at Kitchon & Yes & 67.71 & 3.61 & 108 & 11022 & ค คคค1* * \\
\hline 20 & Nolse level at hichien & No & 54.44 & 7.13 & 490 & 11.922 & 0.0001 \\
\hline 24 & Relative Humidity at & Yes & 40.98 & 13.27 & 498 & 3403 & 0001 * \\
\hline & Kitchen & No & 36.43 & 7.68 & & 0.400 & \\
\hline
\end{tabular}

Test of significance- Independent t-test at 0.05 level of significance; *Significant 


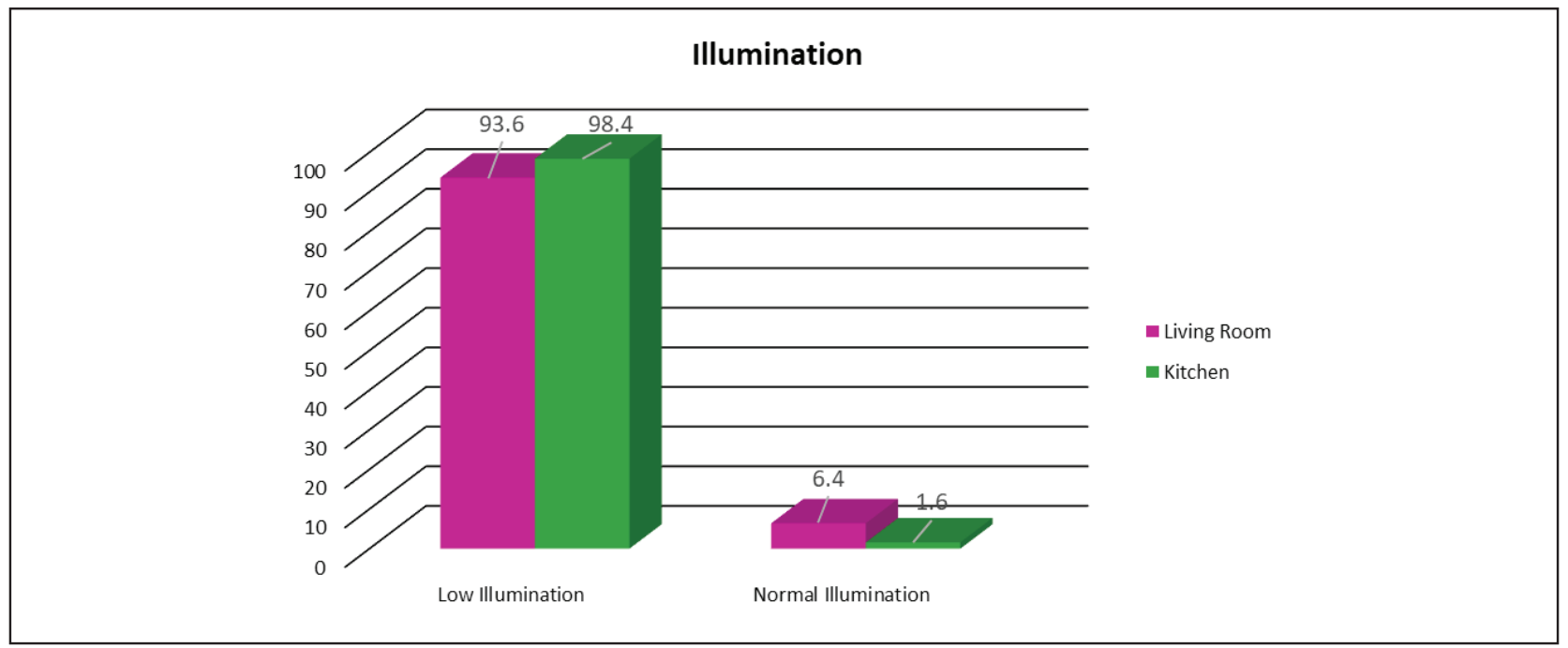

Figure 1: Percentage distribution of Illumination in the living room and Kitchen

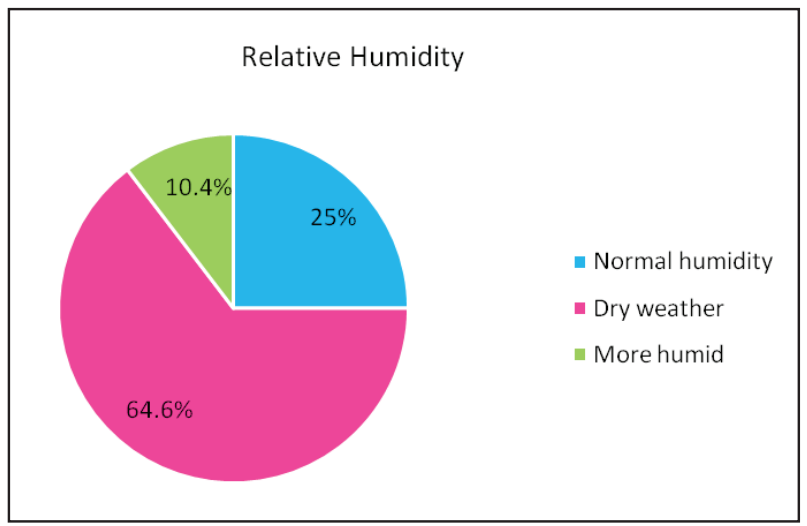

Figure 2: Percentage distribution of humidity in the living room and Kitchen

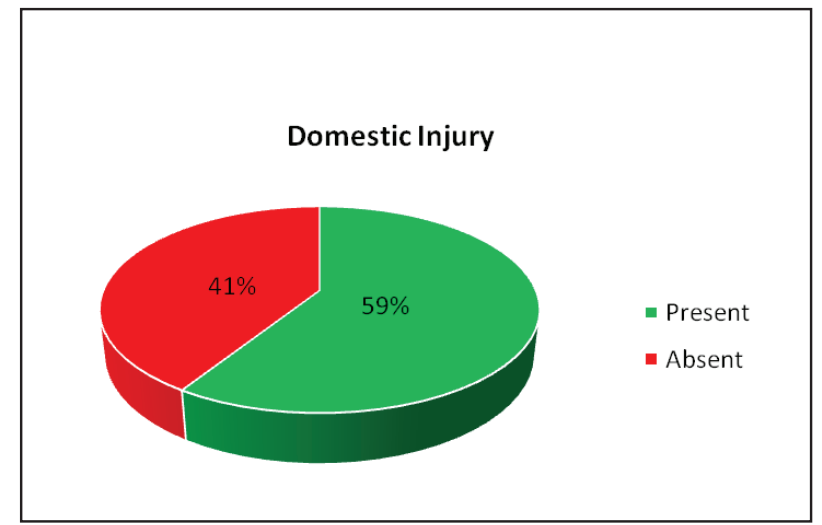

Figure 3: Pie diagram showing the percentage distribution of domestic injury

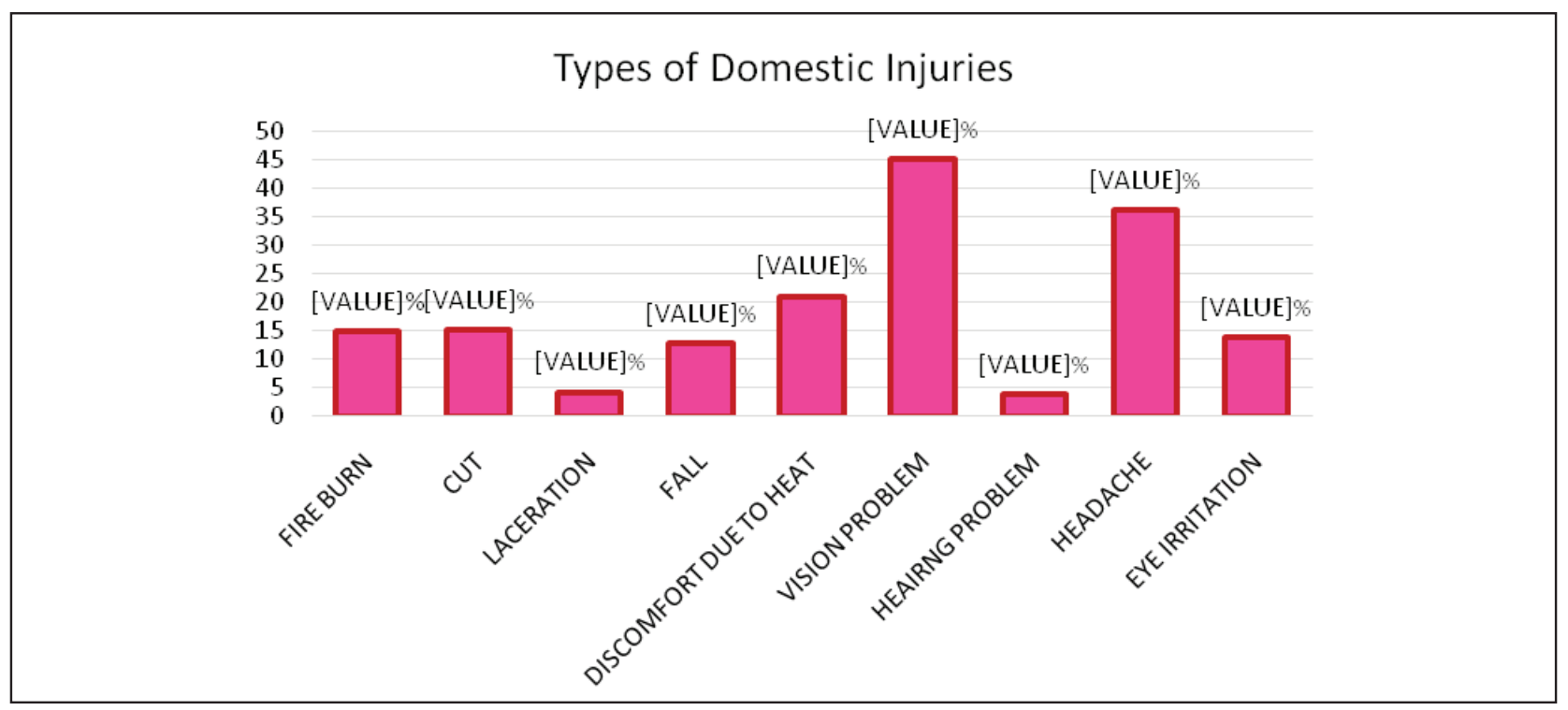

Figure 4: Types of domestic injuries 


\section{Discussion}

The current study has found that a major number (59\%) of housewives had suffered from various domestic injuries. The majority of them were suffering from vision problems $(45.1 \%)$, headache $(36 \%)$, and $15 \%$ got cut and $14.8 \%$ had fire burn incidents. Eye irritation $(13.8 \%)$ and fall on the floor (12.8\%) were the other two common accidents found among these housewives.

A study by Hmingthanzuala et.al in 2011 , showed some similar household injuries like cuts and lacerations $(57.1 \%)$ as the most common accident followed by falls (18.5\%), burn and scald (13.6\%). ${ }^{5}$ The present study also encountered cuts and lacerations (19.4\%), fall $(12.8 \%)$ as common injury at home.

Troup et. al (1981) mentioned that while working at home 3 types of interaction occurs between housewives and the environment. Those are physical agents, chemical agents, and mechanical agents. Physical agents are heat, cold, humidity, noise, light, vibrations, etc. ${ }^{1}$ This study supports the findings of the present study as in terms of factors causing domestic injury assessed were the physical agents, chemical agents, and mechanical agents only. This current study has found a significant association of cut with illumination in the living room $(p=0.002)$, the noise level in the living room $(p=0.001)$, the noise level in the kitchen $(p=0.006)$, relative humidity in the kitchen $(p=0.027)$, and temperature in the kitchen $(p=0.029)$ which denotes that these physical agents are the potential risk factors which may cause cut or other household injuries among housewives.

The present study found a high sound level $(100 \%)$ in the bedroom (56.89 dBA) and living room ( $64.24 \mathrm{dBA})$. Occurrences of laceration were found significantly associated with the noise level in the living room $(p=0.036)$. Fall was associated with the noise level in the bedroom $(p=0.0001)$, the noise level in the living room $(p=0.005)$, and the noise level in the kitchen $(p=0.0001)$. It has been found (Julie Hatfield 2002) that, workers who those been exposed to occupational noise, affect their cognitive task performance. The cognitive and motivational parameters of an individual impair due to environmental noise. There was some significant evidence for emotional disturbances such as depression and anxiety are the result of noise exposure at work. ${ }^{9}$ Occupational exposure to noise had a potential risk factor to generate numerous adverse health effects. ${ }^{10}$ Several studies have established the causal or contribute impact of occupational noise on the occurrence of various accidents. ${ }^{11}$ Recent publications except one ${ }^{12}$ suggest an exposureresponse relationship between noise exposure or hearing impairment and accident risk. ${ }^{13}$

Low illumination is also a potential risk factor, it causes misjudgment of the position, shape, or rapidity of an object that can lead to incidents and injury. Quality of work, specifically in situations where precision is required overall productivity can reduce due to poor illumination. Eye strains, eye discomfort (burning, etc.), and headaches were found as the symptoms of exposure to poor illumination at the workplace. ${ }^{14}$ Both qualitative and quantitative aspects of workplace illumination were considered by many researchers as the key factors determining the employees' productivity. The working promptness, excellence, interruptions, truancy, and accident rate were all affected by the environmental lighting conditions. ${ }^{15}$ This study found $93.6 \%$ of the living room as well $98.4 \%$ of the kitchen of this community had low illumination. Significantly vision problem was associated with illumination at the living room and illumination at the kitchen (both $p=0.0001$ ). Factors causing headache were found as illumination in the living room $(p=0.033)$ and illumination in the kitchen $(p=0.018)$. Eye irritation was found significantly associated with illumination in the living room $(p=0.0118)$ and illumination in the kitchen $(p=0.001)$. Visual discomfort and physiological strain such as headaches, eyestrain, migraine, back pain, neck pain among housewives were primarily connected with inadequate lighting in the working place and most cases decrease work performance and efficiency.

Along with the above-mentioned causes hot (100\%) and dry (64.6\%) kitchen environment also affect housewives' physical performance. Many ecological studies have revealed that extremely hot weather contributes to excess morbidity and mortality in the community. ${ }^{16}$

\section{Conclusion}

The study concluded that housewives are exposed to various physical agents at their own home, which contribute to the prevalence of various types of domestic injuries among them. Housewives themselves and family members have to be aware of those physical agents present in their home and silently causing domestic injuries. 


\section{Acknowledgment}

Researchers thank all Panchayat for permitting them to conduct the study in their area; also extend their

\section{References}

1. Troup JD, Martin JW, Lloyd DC. Back pain in industry: A prospective survey. Spine (Phila Pa 1976). 1981 Jan-Feb;6(1):61-9.

2. Naija H. Domestic accidents; causes and ways to prevent them. Home and Garden [Internet]. 2013 June 13 [cited on 2019 Aug 10]. Available from: https://www.habanaija.com/domestic-accidentscauses-and-ways-to-prevent-them/

3. World Health Organization. Housing \& Health. WHO [Internet]; 2021 [cited on 21.2.2021]. Available from: https://www.euro.who.int/en/health-topics/ environment-and-health/Housing-and-health/ housing-and-health.

4. Gowri S, Vijaya NA, Powar R, Honnungar R, Mallapur M D. Epidemiology and Outcome of Burn Injuries. J Indian Acad Forensic Med. 2012 OctDec;34(4):312-4.

5. Hmingthanzuala, Devi HS, Singh TG. Domestic Accidents in an Urban Health Training Centre. Indian Medical Gazette. 2011 Dec;CXLV(12):476-80.

6. Galal S; Working with families to reduce the risk of home accidents in children. East MeditrHlth J1999;5:572-82.

7. Park K. Preventive and social medicine. 20th ed. Jabalpur: M/s Banarasidas Bhanot; 2009.

8. World Health Organization. Guideline Values Noise [Internet]. Geneva: WHO; 2021[cited on 21.2.2021]. Available at :https://www.who.int/docstore/peh/noise/ Comnoise-4.pdf

9. Hatfield J, Job RF Soames, Hede A J, Carter N L, Peploe P, Taylor R, Morrell S. Human response to environmental noise: The role of perceived control. thank to all the participants of the study, who agreed voluntarily to be a part of this project.

International Journal of Behavioral Medicine. 2002;9(4):341-59.

10. Berglund B, Lindvall T, Schwela DH. Guidelines for Community Noise. Geneva: World Health Organization (WHO); 1999:p.159

11. Cantley LF, Galusha D, Cullen MR, Dixon-Ernst C, Rabinowitz PM, Neitzel RL Scand J. Association between ambient noise exposure, hearing acuity, and risk of acute occupational injury. Work Environ Health. 2015;41(1):75-83.

12. Kling RN, Demers PA, Alamgir H, Davies HW. Noise exposure and serious injury to active sawmill workers in British Columbia.Occup Environ Med. 2012;69(3):211-6.

13. Girard SA, Leroux $T$, Verreault $R$, Courteau $M$, Picard M, Turcotte F, Baril J Can J. Falls risk and hospitalization among retired workers with occupational noise-induced hearing loss. Aging. 2014;33(1):84-91.

14. Canadian Center for Occupational Health and Safety (CCOHS). OSH Answers Fact Sheets- Lighting Ergonomics- Survey and Solutions [Internet]. Canada: CCOHS. 2021 [cited on 21.2.2021]. Available at: https://www.ccohs.ca/oshanswers/ergonomics/ lighting_survey.html\#: :text=Poor $\% 20$ lighting $\% 20$ can\%20affect $\% 20$ the, and $\% 20$ headaches.

15. van Bommel WJM. Non-visual biological effect of lighting and the practical meaning for lighting for work. Applied Ergonomics. 2006;37(4):461-66.

16. Bi $P$, Williams $S$, Loughnan $M$, Lloyd $G$, Hansen A, Kjellstrom T, Dear K, Saniotis A. The effects of extreme heat on human mortality and morbidity in Australia: implications for public health. Asia Pac J Public Health. 2011;23(2):27S-36. 